\title{
FGF18 inhibits MC3T3-E1 cell osteogenic differentiation via the ERK signaling pathway
}

\author{
FENG ZHAI ${ }^{1-3^{*}}$, NA SONG $^{1 *}$, JISHENG MA $^{4}$, WEIYUE GONG ${ }^{4}$, HAISHAN TIAN $^{4}$, \\ XIAOKUN $\mathrm{LI}^{4}, \mathrm{CHAO}^{2} \mathrm{JING}^{4}$ and HAIJUN WANG ${ }^{5}$
}

\author{
${ }^{1}$ Department of Molecular Biology and Biochemistry, Xinxiang Medical University, Xinxiang, Henan 453003; \\ ${ }^{2}$ Department of Technology, Jiangxi Jimin Kexin Pharmaceutical Co., Ltd., Yichun, Jiangxi 336000; ${ }^{3}$ College of \\ Traditional Chinese Medicine, Jilin Agricultural University, Changchun, Jilin 130118; ${ }^{4}$ Department of Biopharmaceuticals, \\ School of Pharmaceutical Science, Wenzhou Medical University, Wenzhou, Zhejiang 325035; ${ }^{5}$ Department of \\ Pathology, School of Basic Medical Sciences, Xinxiang Medical University, Xinxiang, Henan 453003, P.R. China
}

Received January 28, 2016; Accepted May 12, 2017

DOI: $10.3892 / \mathrm{mmr} .2017 .7088$

\begin{abstract}
Fibroblast growth factor (FGF) 18 is a member of the FGF family and serves a key role in skeletal growth and development. The present study investigated the effect of FGF18 on pre-osteoblast MC3T3-E1 cells and the signaling pathways involved by performing an alkaline phosphatase (ALP) assay and reverse transcription-quantitative polymerase chain reaction. MC3T3-E1 cells incubated in a culture medium supplemented with FGF18 exhibited increased viability when compared with the untreated control cells. In addition, ALP activity was decreased in MC3T3-E1 cells treated with FGF18 plus an osteogenic medium (OM) for 7 and 14 days when compared with untreated and OM-treated controls. Reverse transcription-quantitative polymerase chain reaction (RT-qPCR) results demonstrated that the expression of osteoblastic-associated genes was significantly repressed in FGF18 plus OM-treated MC3T3-E1 cells, including ALP, collagen type I, osteocalcin, bone sialo protein and osterix. These results suggested that the expression levels of genes associated with osteogenesis were mainly repressed. In addition, combined treatment of MC3T3-E1 cells with OM and FGF18 led to a significant reduction in mineral deposition when compared
\end{abstract}

Correspondence to: Dr Haijun Wang, Department of Pathology, School of Basic Medical Sciences, Xinxiang Medical University, 601 Jinsui Road, Xinxiang, Henan 453003, P.R. China

E-mail:wnavy200299@163.com

Dr Chao Jiang, Department of Biopharmaceuticals, School of Pharmaceutical Science, Wenzhou Medical University, Qiuzhen Building 11A, Chashan College Park, Wenzhou, Zhejiang 325035, P.R. China

E-mail: chaojiang2015@163.com

*Contributed equally

Key words: MC3T3-E1, fibroblast growth factor 18, proliferation, differentiation with the OM-only treated group. Furthermore, FGF18 activated the extracellular signal-regulated kinase pathway in MC3T3-E1 cells, which may have been responsible for the observed decrease in the expression of osteoblastic-associated genes. In conclusion, the results suggest that FGF18 may be involved in MC3T3-E1 cell proliferation and osteoblastic differentiation.

\section{Introduction}

The formation of bone tissue involves two major processes; one of which involves the continuous absorption of old bone tissue by osteoclasts, while the other involves the reconstruction of new bone tissues by osteoblasts (1). Numerous processes are involved in bone formation, including the regulation of osteoblast proliferation, bone matrix maturation, matrix mineralization and apoptosis $(2,3)$. These processes are mediated by bone morphogenetic protein 2, alkaline phosphatase (ALP) and several members of the fibroblast growth factor (FGF) family (4-6).

FGFs are potent mitogens for a wide variety of cells of mesenchymal and neuroectodermal origin $(7,8)$. In addition, FGFs serve a functional role in the differentiation of a variety of cell types, and are involved in a number of developmental processes, including brain patterning, branching morphogenesis and limb development (9). Several FGF family members are active in bone development, including FGF1, FGF2, FGF8, FGF10 and FGF18 (10).

First reported in 1998, FGF18 is a growth factor that exhibits a high homology to FGF8 (11-13). FGF18 is an FGF that has been demonstrated to serve a key role in skeletal growth and development (14). The majority of studies regarding FGF18 have focused on its role in cartilage formation $(15,16)$. A number of studies have demonstrated that FGF18 serves a role in bone formation $(17,18)$, in addition to a positive role in mesenchymal stem cells during bone development $(19,20)$. However, Shimoaka et al (21) reported that FGF18 inhibited differentiation and matrix synthesis, and identified the mitogenic action of FGF18 in primary osteoblasts. In order to determine whether these contradicting results may have been 
due to use of different cell types, and to determine the effects of FGF18 on osteogenic differentiation, the present study investigated the effect of FGF18 on the viability and differentiation of MC3T3-E1 cells and the potential underlying mechanisms involved. The MC3T3-E1 cell line possesses the ability to self-renew and differentiate into osteoblasts, and is used as a model to study the osteogenic process in vitro $(22,23)$.

The aim of the present study was to investigate the role of FGF18 in MC3T3-E1 cells, and examine its effects on the viability and osteoblastic differentiation of these cells in vitro.

\section{Materials and methods}

Cells culture and reagents. The pre-osteoblastic MC3T3-E1 cell line was obtained from the American Type Culture Collection (Manassas, VA, USA; CRL-2593). L-ascorbic acid, $\beta$-glycerophosphate, dexamethasone and the MTT reagent were purchased from Sigma-Aldrich; Merck KGaA (Darmstadt, Germany). The ALP assay kit was obtained from Nanjing Jiancheng Bioengineering Institute (Nanjing, China; cat. no. A059-2-96T). Recombinant human FGF18 was obtained from the Engineering Research Center of Bioreactor and Pharmaceutical Development (Ministry of Education, Jilin Agricultural University, Changchun, China). MC3T3-E1 cells were cultured in minimum essential medium Eagle- $\alpha$ (MEM- $\alpha$; cat. no. 32561037) supplemented with $12 \%$ fetal bovine serum (FBS; cat. no. 16000044) and $1 \%$ penicillin/streptomycin (cat. no. 10378016; all Thermo Fisher Scientific, Inc., Waltham, MA, USA) at $37^{\circ} \mathrm{C}$ in a $5 \% \mathrm{CO}_{2}$ humidified incubator. Osteogenic medium (OM) consisted of $50 \mu \mathrm{g} / \mathrm{ml} \mathrm{L}$-ascorbic acid, $10 \mathrm{mM} \beta$-glycerophosphate and $10^{-7}$ $\mathrm{M}$ dexamethasone in MEM- $\alpha$. Cells were cultured in 24-well cell plates at a density of $2 \times 10^{5}$ cells/well, and treated with $40 \mathrm{ng} / \mathrm{ml}$ FGF18 for 7 and 14 days. The OM or FGF18 plus OM were refreshed every two days for 7 and 14 days. Cells that were cultured with MEM- $\alpha$ supplemented with 12\% FBS and $1 \%$ penicillin/streptomycin were used as the control.

MTT assay. MC3T3-E1 cells were seeded at $2 \times 10^{3}$ cells/well in 96-well plates, and cultured in $200 \mu \mathrm{l}$ complete growth medium supplemented with $0,5,10,20,40,80,160$ or $320 \mathrm{ng} / \mathrm{ml}$ FGF18 for $72 \mathrm{~h}$. To each well $25 \mu \mathrm{l}$ MTT solution $(5 \mathrm{mg} / \mathrm{ml})$ was then added, and cells were incubated for $4 \mathrm{~h}$. The medium was discarded and $150 \mu$ l dimethyl sulfoxide was added to each well. Following incubation for $30 \mathrm{~min}$ at room temperature, the absorbance at $490 \mathrm{~nm}$ was immediately measured using the SpectraMax i3x Multi-Mode Detection Platform (Molecular Devices, LLC, Sunnyvale, CA, USA).

ALP activity. ALP activity was analyzed colorimetrically using an ALP assay kit. Cells were cultured in 24-well cell plates at a density of $1 \times 10^{5}$ cells/well, and following 7 and 14 days of exposure to control medium, OM or OM plus $40 \mathrm{ng} / \mathrm{ml} \mathrm{FGF18,} \mathrm{the} \mathrm{culture} \mathrm{medium} \mathrm{was} \mathrm{removed} \mathrm{and} \mathrm{cells}$ were washed twice with phosphate-buffered saline (PBS) and solubilized in $0.1 \%$ Triton X-100 (buffered in 0.1 M PBS; $\mathrm{pH} 7.3$ ) at $4^{\circ} \mathrm{C}$ for $1 \mathrm{~h}$. Following centrifugation at $200 \mathrm{x} \mathrm{g}$ for $5 \mathrm{~min}$ at room temperature, ALP activity in the supernatant was determined by measuring the optical density (OD) at 405 and $562 \mathrm{~nm}$ using the SpectraMax i3x Multi-Mode Detection
Platform (Molecular Devices, LLC), and the OD405/OD562 ratio was then calculated. Total protein was quantified using a bicinchoninic acid assay (BCA) kit (cat. no. BCA1-1KT; Sigma-Aldrich; Merck KGaA) to calculate the mean OD/mg protein.

Analysis of osteogenic-associated gene expression by reverse transcription-quantitative polymerase chain reaction (RT-qPCR). The effects of $40 \mathrm{ng} / \mathrm{ml}$ FGF18 on the mRNA expression levels of six osteogenic-associated genes including ALP, collagen type I ( $\mathrm{Col} \mathrm{I})$, osteocalcin (OCN), bone sialo protein (BSP), osterix (OSX) and runt-related transcription factor 2 (Runx 2) were examined. Total RNA was extracted from $1 \times 10^{5}$ MC3T3-E1 cells in a 24-well plate using RNAiso Plus reagent (cat. no. D9108A; Takara Biotechnology Co., Ltd., Dalian, China) on days 3, 7 and 14 of culture according to the manufacturer's instructions. The total RNA concentration was determined using a NanoDrop spectrophotometer (cat. no. ND-2000; Thermo Fisher Scientific, Inc., USA). A total of $1 \mu \mathrm{g}$ RNA was reverse transcribed to cDNA using the PrimeScript ${ }^{\mathrm{TM}}$ RT reagent kit (cat. no. RR037A; Takara Biotechnology Co., Ltd.) according to the manufacturer's protocol. qPCR was performed in $20 \mu \mathrm{l}$ reaction volumes containing SYBR-Green master mix (Roche Applied Science, Penzberg, Germany). The primer sequences (Table I) were designed specifically using Primer Express Software (version 3.0.1; Thermo Fisher Scientific, Inc.), and $\beta$-actin served as the endogenous control. Relative mRNA expression was calculated using the comparative $2^{-\Delta \Delta \mathrm{Cq}}$ method (24).

Alizarin red $S$ (ARS) staining. At day 14 of treatment with control, OM or OM plus $40 \mathrm{ng} / \mathrm{ml}$ FGF18, 1x10 5 MC3T3-E1 cells were fixed with $4 \%(\mathrm{w} / \mathrm{v})$ paraformaldehyde for $15 \mathrm{~min}$ at room temperature, rinsed with PBS and stained with $1 \mathrm{ml} /$ well $0.1 \%$ (w/v) ARS (Sigma-Aldrich; Merck KGaA; pH 8.3) for $20 \mathrm{~min}$ at room temperature. Cells were then washed with PBS and observed under an inverted light microscope. Stained cells were treated with $10 \%(\mathrm{w} / \mathrm{v}) \mathrm{SDS}$ at $37^{\circ} \mathrm{C}$ overnight to extract the dye (25), and the level of mineralization was quantified by measuring the absorbance at $405 \mathrm{~nm}$ using the SpectraMax i3x Multi-Mode Detection Platform (Molecular Devices, LLC).

Western blot analysis. Cells $\left(3 \times 10^{5}\right)$ were seeded in 6-well cell plate when confluence reached $75 \%$, and were then treated with $\mathrm{OM}$ medium or OM medium plus $40 \mathrm{ng} / \mathrm{ml}$ FGF18 for $24 \mathrm{~h}$ at $37^{\circ} \mathrm{C}$. The cells were lysed in cold lysis buffer $(60 \mathrm{mM}$ Tris- $\mathrm{HCl}$ at $\mathrm{pH} 7.4,150 \mathrm{mM} \mathrm{NaCl}, 0.25 \%$ SDS and $1 \%$ Tergitol-type NP40) containing $10 \mathrm{mM} \mathrm{NaF}, 1 \mathrm{mM} \mathrm{Na} \mathrm{VO}_{4}$ and complete protease inhibitor (Roche Diagnostics, Basel, Switzerland) for $30 \mathrm{~min}$ on ice and were then centrifuged at 10,000 $\mathrm{x} \mathrm{g}$ and $4^{\circ} \mathrm{C}$ for 15 min. The Enhanced BCA Protein Assay kit (cat no. P0010; Beyotime Institute of Biotechnology, Haimen, China) was used for protein quantification. A total of $40 \mu \mathrm{g}$ protein was separated by $12 \%$ SDS-PAGE and transferred onto a $0.45 \mu \mathrm{m}$ polyvinylidene difluoride membrane (Whatman plc; GE Healthcare Life Sciences, Little Chalfont, UK). The membranes were blocked with $5 \%$ non-fat milk for $20 \mathrm{~min}$ at room temperature, and then incubated with the primary antibodies (dilution, 1:1,000) at $4^{\circ} \mathrm{C}$ overnight, followed by incubation with the secondary antibody (dilution, 1:3,000) at 
Table I. Primer sequences used to detect the expression of Mus musculus osteogenic-associated genes.

\begin{tabular}{lll}
\hline Gene & \multicolumn{1}{c}{ Forward (5'-3') } & \multicolumn{1}{c}{ Reverse (5'-3') } \\
\hline$\beta$-actin & AGAGGGAAATCGTGCGTGAC & CAAGAAGGAAGGCTGGAAAA \\
ALP & GCTGATCATTCCCACGTTTC & CTGGGCCTGGTAGTTGTTGT \\
BSP & CAGAGGAGGCAAGCGTCACT & CTGTCTGGGTGCCAACACTG \\
OSX & ACCAGGTCCAGGCAACAC & GGGCAGTCGCAGGTAGAA \\
OCN & CCGGGAGCAGTGTGAGCTTA & ATAGATGCGTTTGTAGGCGGTC \\
Col I & CCAGCGGTGAAGAAGGAAAGAG & GAACCACGATTGCCAGGAGGAC \\
Runx2 & CCAACTTCCTGTGCTCCGTG & TCTTGCCTCGTCCGCTCC
\end{tabular}

ALP, alkaline phosphatase; BSP, bone sialo protein; OSX, osterix; OCN, osteocalcin; COL-1, collagen type I; Runx2, runt-related transcription factor 2 .

room temperature for $30 \mathrm{~min}$. Enhanced chemiluminescence Plus (cat. no. P0018; Beyotime Institute of Biotechnology) and the ChemiDoc ${ }^{\mathrm{TM}}$ MP Imaging System (Bio-Rad Laboratories, Inc., Hercules, CA, USA) were used to visualize protein bands, according to the manufacturer's instructions. The rabbit anti-ERK1/2 (cat. no. sc-292838), rabbit anti-phosphorylated (p)-ERK1/2 (cat. no. sc-101760), rabbit anti- $\beta$-actin (cat. no. sc-1616) and the horseradish peroxidase-conjugated goat anti-rabbit secondary IgG antibody (cat. no. sc-2004) were purchased from Santa Cruz Biotechnology, Inc. (Dallas, TX, USA). $\beta$-actin was used as a loading control.

Statistical analysis. Each treatment was performed in triplicate. The results were analyzed by one-way analysis of variance followed by the Dunnett's post hoc test. Statistical analysis was performed using SPSS software (version 18.0; SPSS, Inc., Chicago, IL, USA). The results are presented as the mean \pm standard deviation. $\mathrm{P}<0.05$ was considered to indicate a statistically significant difference.

\section{Results}

FGF18 enhances the viability of MC3T3-E1 cells. The effect of FGF18 on the viability of MC3T3-E1 cells was examined using an MTT assay. As presented in Fig. 1, FGF18 significantly increased the viability of MC3T3-E1 cells in a dose-dependent manner, and the OD value remained stable following $40 \mathrm{ng} / \mathrm{ml}$ FGF18. Based on these results, $40 \mathrm{ng} / \mathrm{ml}$ FGF18 was considered to be an effective dose, as it enhanced the viability of MC3T3-E1 cells by $\sim 41 \%$ at $72 \mathrm{~h}$ when compared with untreated controls. This dosage was therefore used in subsequent experiments.

FGF18 decreased ALP activity in MC3T3-E1 cells. The effect of FGF18 on ALP activity in MC3T3-E1 cells was then determined. Following exposure to control media or OM with or without $40 \mathrm{ng} / \mathrm{ml} \mathrm{FGF18,} \mathrm{cells} \mathrm{were} \mathrm{harvested} \mathrm{at} 7$ and 14 days to assess ALP activity. As shown in Fig. 2, ALP activity in the $\mathrm{OM}+\mathrm{FGF} 18$ treated group was significantly higher on day 14 when compared with day $7(\mathrm{P}<0.01)$. In addition, cells exposed to OM plus FGF18 demonstrated a significant reduction in ALP activity on day 7 when compared with the OM and control groups $\left({ }^{\# \# \#} \mathrm{P}<0.001\right.$ vs. $\mathrm{OM} ;{ }^{* *} \mathrm{P}<0.01$ vs. control;

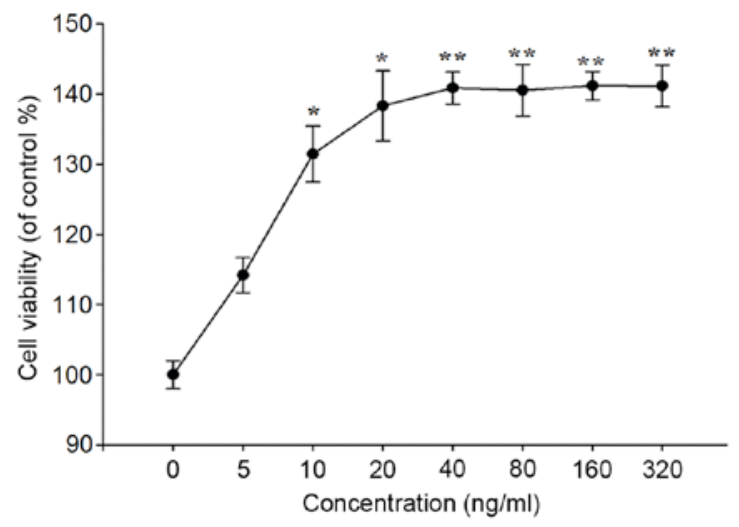

Figure 1. Effect of FGF18 on the viability of MC3T3-E1 cells. MC3T3-E1 cells were treated with $0,5,10,20,40,80,160$ and $320 \mathrm{ng} / \mathrm{ml} \mathrm{FGF18} \mathrm{for}$ $72 \mathrm{~h}$, and cell viability was assessed using an MTT assay. The results are expressed as the mean \pm standard deviation $(n=3)$. ${ }^{*} \mathrm{P}<0.05$ and ${ }^{* *} \mathrm{P}<0.01$ vs control (0 ng/ml FGF18). FGF18, fibroblast growth factor 18.

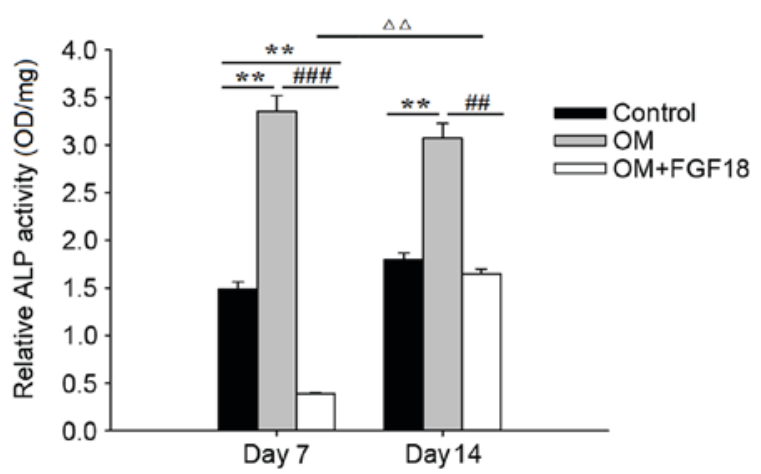

Figure 2. Effect of FGF18 on ALP activity in MC3T3-E1 cells. ALP activity was examined in MC3T3-E1 cells cultured in control, OM or OM plus FGF18 for 7 and 14 days. ${ }^{* *} \mathrm{P}<0.01$ vs. control; ${ }^{\# \#} \mathrm{P}<0.01$ and ${ }^{\# \#} \mathrm{P}<0.001$ vs. $\mathrm{OM} ;{ }^{\Delta \Delta} \mathrm{P}<0.01$ for $\mathrm{OM}+\mathrm{FGF} 18$, Day 14 vs. Day 7. FGF18, fibroblast growth factor 18; ALP, alkaline phosphatase; OM, osteogenic medium.

Fig. 2). These results suggest that treatment with FGF18 decreases ALP activity in MC3T3-E1 cells.

FGF18 repressed the expression of osteoblastic-associated genes in MC3T3-E1 cells. The effects of FGF18 on the osteogenic differentiation of MC3T3-E1 cells was investigated by 
A

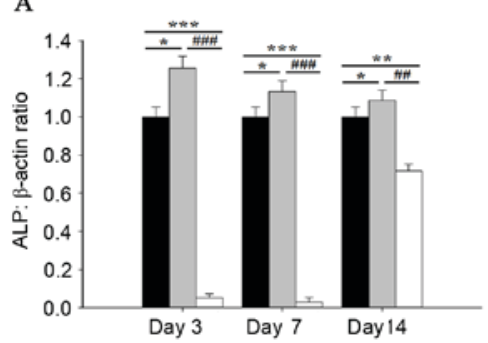

C

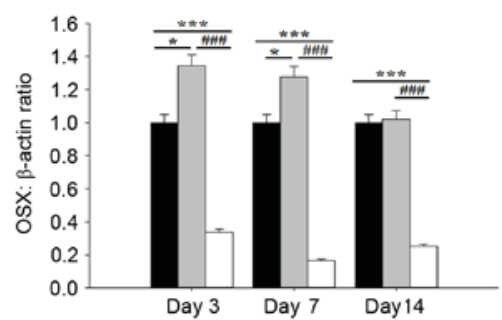

$\mathrm{E}$

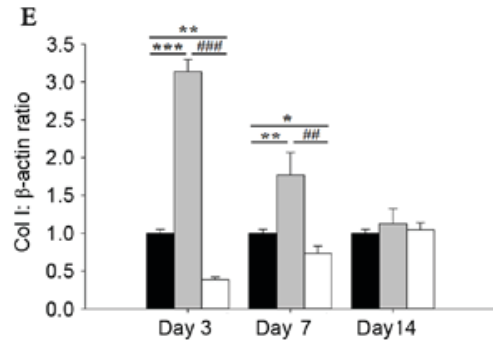

B

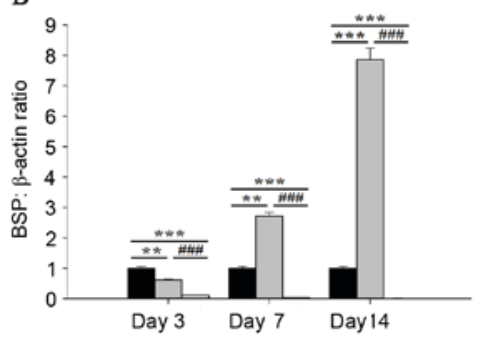

D
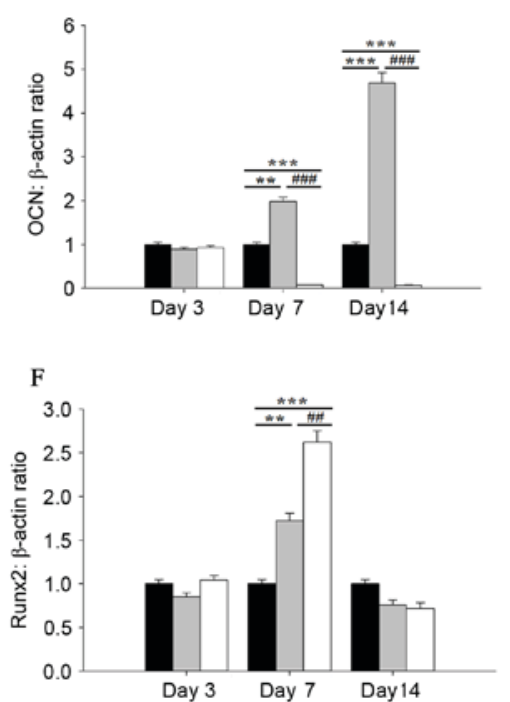

Figure 3. Expression levels of osteogenic-associated genes in MC3T3-E1 cells treated with FGF18. The mRNA expression levels of (A) ALP, (B) BSP, (C) OSX, (D) OCN, (E) COL-1 and (F) Runx2. ${ }^{*} \mathrm{P}<0.05,{ }^{* *} \mathrm{P}<0.01$ and ${ }^{* * *} \mathrm{P}<0.001$ vs. control; ${ }^{\# \#} \mathrm{P}<0.01$ and ${ }^{\# \# "} \mathrm{P}<0.001$ vs. OM. Black bars, control group; gray bars, OM group; white bars, OM+FGF18; FGF18, fibroblast growth factor 18; ALP, alkaline phosphatase; BSP, bone sialo protein; OSX, osterix; OCN, osteocalcin; COL-1, collagen type I; Runx2, runt-related transcription factor 2; OM, osteogenic medium.

A

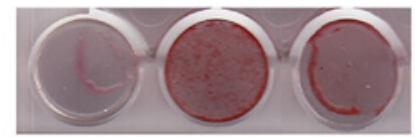

B

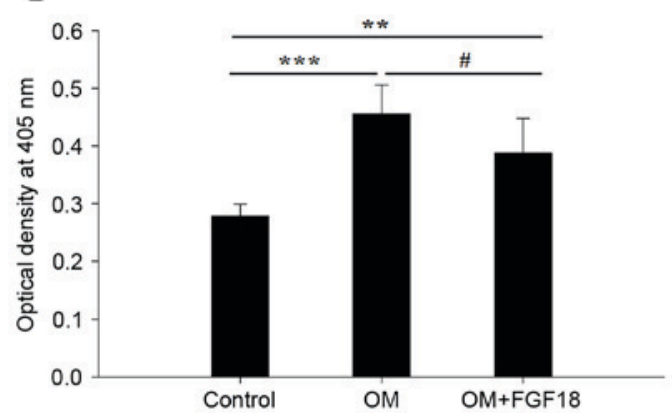

Figure 4. Effect of FGF18 on mineral deposition in MC3T3-E1 cells. (A) Alzarin red S staining and (B) quantification of mineral deposition. ${ }^{* * *} \mathrm{P}<0.01$ and ${ }^{* * * *} \mathrm{P}<0.001$ vs. control; ${ }^{*} \mathrm{P}<0.05$ vs. OM. FGF18, fibroblast growth factor 18; OM, osteogenic medium.

examining the expression of osteogenic-associated genes, including Col I, Runx2, OSX, OCN, ALP and BSP, at days 3, 7 and 14 of treatment. FGF18 was observed to decrease the expression of ALP, BSP, OSX, OCN and Col I when compared with control and OM-only treated cells (Fig. 3A-E). By contrast, FGF18 treatment significantly enhanced the expression of

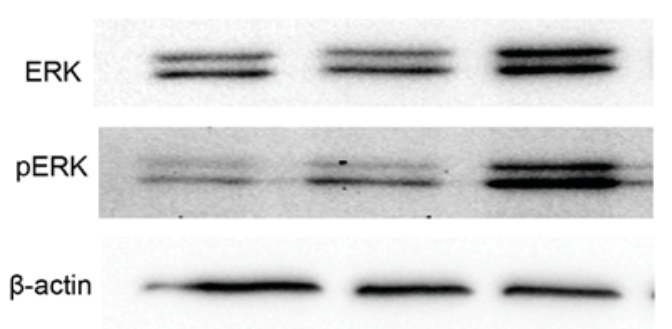

Figure 5. Western blot analysis of FGF18-mediated activation of ERK signaling pathways in MC3T3-E1 cells. $\beta$-actin served as a loading control. Lane 1, control group; lane 2, OM group; lane 3, OM+FGF18 group; FGF18, fibroblast growth factor 18; p-ERK, phosphorylated-extracellular signal-regulated kinase.

Runx 2 at day 7, whereas its expression was decreased at day 14 when compared with the control and OM groups (Fig. 3F). Runx2 is a key transcription factor involved in osteoblast and chondrogenic differentiation (26). Therefore, it has been hypothesized that Runx 2 may be associated with the positive role of FGF18 on chondrogenic differentiation.

FGF18 repressed mineral deposition in MC3T3-E1 cells. To determine the effect of FGF18 on the level of mineralization, ARS staining was employed to visualize mineral deposition in FGF18-treated MC3T3-E1 cells in vitro. As shown in Fig. 4, 
untreated control MC3T3-E1 pre-osteoblasts exhibited significantly lower levels of mineralization when compared with the OM group. In addition, mineralization was significantly reduced in the OM plus FGF18 group when compared with the OM group (Fig. 4). These results suggest that FGF18 significantly inhibited mineral deposition.

FGF18 activates ERK signaling pathways in MC3T3-E1 cells. The mechanism by which FGF18 functions in osteogenesis was then investigated. As shown in Fig. 5, FGF18 treatment of MC3T3-E1 cells increased the protein expression levels of ERK and phosphorylated-ERK when compared with control and OM groups, which suggests that the ERK signaling pathway was activated. These results suggest that FGF18 may repress MC3T3-E1 differentiation and mineral deposition via the ERK signaling pathway.

\section{Discussion}

The results of the present study demonstrated that FGF18 increased the viability of pre-osteoblastic MC3T3-E1 cells and decreased the expression of genes that serve a functional role in osteoblast differentiation and mineral deposition. In addition, FGF18 was observed to increase cell viability in a dose-dependent manner, and increased markedly at a dose of $0-40 \mathrm{ng} / \mathrm{ml}$. At concentrations of FGF18 $\geq 40 \mathrm{ng} / \mathrm{ml}$, cell viability reached a plateau and no significant difference was observed at an increased dose. Therefore, 40 ng/ml FGF18 was selected as the working concentration for downstream experiments.

In the present study, FGF18 served a negative role in MC3T3-E1 osteogenic differentiation, as it was observed to repress the expression of genes associated with osteogenesis and mineral deposition. FGF18 inhibited ALP activity when compared with the OM-only treated group. In addition, FGF18 treatment decreased the expression of ALP, BSP, OSX and OCN which are early markers of MC3T3 differentiation. OSX expression levels were significantly decreased in the FGF18-treated group when compared with FGF18-untreated groups. OSX is a marker of late osteogenesis, and is abundant in mature osteoblasts (27). Col I and OCN are the two major factors involved in bone matrix mineralization, and $\mathrm{Col} \mathrm{I}$ is the most abundant protein. By contrast, OCN is the most abundant non-collagenous bone matrix protein, which is expressed in mature osteoblasts. Runx 2 is an early transcription factor in osteogenesis, and so its expression is noteworthy when compared with other ostebolastic gene markers (27-29). In the present study, treatment of MC3T3-E1 cells with FGF18 increased Runx2 expression to its highest level at day 7, followed by a marked decrease at day 14 , when compared with FGF18-untreated groups. Runx2 is a critical transcriptional regulator of osteoblast and chondrocyte differentiation, as well as a regulator of tumor progression (30). In addition, Runx2 forms a complex with lymphoid enhancer binding factor 1 or transcription factor 4 , which subsequently binds to the corresponding binding site in the FGF18 promoter (31). Therefore, the authors hypothesized that the abnormal expression of Runx2 following FGF18 treatment may have been due to the activation of additional cell signaling pathways by FGF18. This requires further investigation in future studies.
The present study demonstrated that FGF18 reduced mineral deposition in MC3T3-E1 cells, as revealed by ARS staining. Following treatment of cells with FGF18, ARS staining was clearly reduced when compared with the OM group. In addition, it was demonstrated that MC3T3-E1 cells might not be a suitable model for assessing osteogenic differentiation. Following 14 days of incubation with OM, MC3T3-E1 cells exhibited positive ARS staining; however, the staining intensity was not as strong as in primary osteoblasts [as previously reported (32)], nor as strong in bone marrow stromal cells (data not shown), thus it may not be a suitable model.

The present study investigated whether FGF18 may function via the ERK signaling pathway to regulate osteogenesis of MC3T3-E1 cells. The results suggested that FGF18 may suppress the osteogenic differentiation of MC3T3-E1 cells via the ERK signaling pathway. This is a novel hypothesis, and it was demonstrated that the protein expression levels of ERK and phosphorylated ERK were markedly enhanced during exposure to OM plus FGF18. A previous report indicated that endogenous Runx 2 activity in endothelial cells is phosphatidylinositol 3-kinase/ERK-dependent (33). Therefore, it is possible that the abnormal expression of Runx 2 following FGF18 treatment observed in the present study may have been associated with ERK signaling activation. In addition, ERK signaling is known to be involved in mediating cell proliferation and self-renewal (34). Therefore, it is possible that FGF18 repressed the differentiation of MC3T3-E1 cells into mature osteoblasts by maintaining their self-renewing capacity via upregulation of ERK and phosphorylated ERK.

In conclusion, the present study demonstrated that FGF18 increases the viability of MC3T3-E1 cells. In addition, FGF18 serves a negative role in osteogenesis and decreases the expression of osteogenic-associated genes and mineral deposition in MC3T3-E1 cells. The mechanisms by which FGF18 mediates these effects may involve the ERK signaling pathway, as FGF18 was observed to enhance the protein expression levels of ERK and phosphorylated ERK. These results suggest that FGF18 promotes the self-renewal of cells and may suppress MC3T3-E1 osteoblastic maturation via the ERK cell signaling pathway.

\section{Acknowledgements}

The present study was supported by the Doctoral Scientific Research Foundation of Xingxiang Medical University (grant nos. XYBSKYZZ201512 and 201513), the National Natural Science Foundation of China (grant no. 81602132), The Education Department of Henan Province (grant no. 201610472040) and the Key Technologies Research and Development Program of Henan Province, China (grant no. 20166585).

\section{References}

1. Mulari MT, Qu Q, Härkönen PL and Väänänen HK: Osteoblast-like cells complete osteoclastic bone resorption and form new mineralized bone matrix in vitro. Calcif Tissue Int 75: 253-261, 2004.

2. Boyce BF, Rosenberg E, de Papp AE and Duong LT: The osteoclast, bone remodelling and treatment of metabolic bone disease. Eur J Clin Invest 42: 1332-1341, 2012. 
3. Xing L and Boyce BF: Regulation of apoptosis in osteoclasts and osteoblastic cells. Biochem Biophys Res Commun 328: 709-720, 2005.

4. Shen J, James AW, Zhang X, Pang S, Zara JN, Asatrian G, Chiang M, Lee M, Khadarian K, Nguyen A, et al: Novel Wnt regulator NEL-like molecule-1 antagonizes adipogenesis and augments osteogenesis induced by bone morphogenetic protein 2. Am J Pathol 186: 419-434, 2016.

5. Lollobrigida M, Lamazza L, Capuano C, Formisano G, Serra E, Laurito D, Romanelli M, Molinari A and De Biase A: Physical profile and impact of a calcium-incorporated implant surface on preosteoblastic cell morphologic and differentiation parameters: A comparative analysis. Int J Oral Maxillofac Implants 31: 223-231, 2016.

6. Ma JY, Wong KL, Xu ZY, Au KY, Lee NL, Su C, Su WW, Li PB and Shaw PC: N16, a nacreous protein, inhibits osteoclast differentiation and enhances osteogenesis. J Nat Prod 79: 204-212, 2016

7. Ornitz DM and Itoh N: Fibroblast growth factors. Genome Biol 2: REVIEWS3005, 2001.

8. Kang W and Hébert JM: FGF signaling is necessary for neurogenesis in young mice and sufficient to reverse its decline in old mice. J Neurosci 35: 10217-10223, 2015.

9. Moradi M, Riasi A, Ostadhosseini S, Hajian M, Hosseini M, Hosseinnia P and Nasr-Esfahani MH: Expression profile of FGF receptors in preimplantation ovine embryos and the effect of FGF2 and PD173074. Growth Factors 33: 393-400, 2015.

10. Takei Y, Minamizaki T and Yoshiko Y: Functional diversity of fibroblast growth factors in bone formation. Int J Endocrinol 2015 729352, 2015.

11. Ohbayashi N, Hoshikawa M, Kimura S, Yamasaki M, Fukui S and Itoh N: Structure and expression of the mRNA encoding a novel fibroblast growth factor, FGF-18. J Biol Chem 273 : 18161-18164, 1998

12. Fischer S, Draper BW and Neumann CJ: The zebrafish fgf 24 mutant identifies an additional level of Fgf signaling involved in vertebrate forelimb initiation. Development 130: 3515-3524, 2003

13. Maruoka Y, Ohbayashi N, Hoshikawa M, Itoh N, Hogan BL and Furuta Y: Comparison of the expression of three highly related genes, Fgf8, Fgf17 and Fgf18, in the mouse embryo. Mech Dev 74: 175-177, 1998.

14. Moore EE, Bendele AM, Thompson DL, Littau A, Waggie KS, Reardon B and Ellsworth JL: Fibroblast growth factor-18 stimulates chondrogenesis and cartilage repair in a rat mode of injury-induced steoarthritis. Osteoarthritis Cartilage 13: 623-631, 2005

15. Wang Y, Yang T, Liu Y, Zhao W, Zhang Z, Lu M and Zhang W: Decrease of miR-195 promotes chondrocytes proliferation and maintenance of chondrogenic phenotype via targeting FGF-18 pathway. Int J Mol Sci 18: pii: E975, 2017.

16. Bradley EW, Carpio LR, Newton AC and Westendorf JJ: Deletion of the PH-domain and leucine-rich repeat protein phosphatase 1 (Phlpp1) Increases fibroblast growth factor (Fgf) 18 expression and promotes chondrocyte proliferation. J Biol Chem 290: 16272-16280, 2015.

17. Hung IH, Schoenwolf GC, Lewandoski M and Ornitz DM: A combined series of Fgf9 and Fgf18 mutant alleles identifies unique and redundant roles in skeletal development. Dev Biol 411: 72-84, 2016.

18. Nagayama T, Okuhara S, Ota MS, Tachikawa N, Kasugai S and Iseki S: FGF18 accelerates osteoblast differentiation by upregulating Bmp2 expression. Congenit Anom (Kyoto) 53: 83-88, 2013.
19. Zhang Z, Wang Y, Li M, Li J and Wu J: Fibroblast growth factor 18 increases the trophic effects of bone marrow mesenchymal stem cells on chondrocytes isolated from late stage osteoarthritic patients. Stem Cells Int 2014: 125683, 2014.

20. Correa D, Somoza RA, Lin P, Greenberg S, Rom E, Duesler L, Welter JF, Yayon A and Caplan AI: Sequential exposure to fibroblast growth factors (FGF) 2, 9 and 18 enhances hMSC chondrogenic differentiation. Osteoarthritis Cartilage 23: 443-453, 2015.

21. Shimoaka T, Ogasawara T, Yonamine A, Chikazu D, Kawano H, Nakamura K, Itoh $\mathrm{N}$ and Kawaguchi H: Regulation of osteoblast, chondrocyte and osteoclast functions by fibroblast growth factor (FGF)-18 in comparison with FGF-2 and FGF-10. J Biol Chem 277: 7493-7500, 2002.

22. Rendina-Ruedy E, Graef JL, Lightfoot SA, Ritchey JW, Clarke SL, Lucas EA and Smith BJ: Impaired glucose tolerance attenuates bone accrual by promoting the maturation of osteoblasts: Role of Beclin1-mediated autophagy. Bone Rep 5: 199-207, 2016.

23. Ling M, Huang P, Islam S, Heruth DP, Li X, Zhang LQ, Li DY, $\mathrm{Hu} \mathrm{Z}$ and Ye SQ: Epigenetic regulation of Runx2 transcription and osteoblast differentiation by nicotinamide phosphoribosyltransferase. Cell Biosci 7: 27, 2017.

24. Livak KJ and Schmittgen TD: Analysis of relative gene expression data using real-time quantitative PCR and the 2(-Delta Delta C(T)) Method. Methods 25: 402-408, 2001.

25. Song N, Armstrong AD, Li F, Ouyang H and Niyibizi C: Multipotent mesenchymal stem cells from human subacromial bursa: Potential for cell based tendon tissue engineering. Tissue Eng Part A 20: 239-249, 2014.

26. Bruderer M, Richards RG, Alini M and Stoddart MJ: Role and regulation of RUNX2 in osteogenesis. Eur Cell Mater 28: 269-286, 2014

27. Jensen ED, Gopalakrishnan R and Westendorf JJ: Regulation of gene expression in osteoblasts. Biofactors 36: 25-32, 2010

28. Scharnweber D, Born R, Flade K, Roessler S, Stoelzel M and Worch H: Mineralization behaviour of collagen type I immobilized on different substrates. Biomaterials 25: 2371-2380, 2004

29. Raymaekers G, Aerssens J, Van den Eynde R, Peeters J, Geusens P, Devos P and Dequeker J: Alterations of the mineralizaiton profile and osteocalcin concentrations in osteoarthritic cortical iliac crest bone. Calcif Tissue Int 51: 269-275, 1992.

30. Cohen-Solal KA, Boregowda RK and Lasfar A: RUNX2 and the $\mathrm{PI} 3 \mathrm{~K} / \mathrm{AKT}$ axis reciprocal activation as a driving force for tumor progression. Mol Cancer 14: 137, 2015.

31. Reinhold MI and Naski MC: Direct interactions of Runx2 and canonical Wnt signaling induce FGF18. J Biol Chem 282: 3653-3663, 2007.

32. Li F, Song N, Tombran-Tink J and Niyibizi C: Pigment epithelium derived factor suppresses expression of Sost/Sclerostin by osteocytes: Implication for its role in bone matrix mineralization. J Cell Physiol 230: 1243-1249, 2015.

33. Qiao M, Shapiro P, Kumar R and Passaniti A: Insulin-like growth factor-1 regulates endogenous RUNX2 activity in endothelial cells through a phosphatidylinositol 3-kinase/ERK-dependent and Akt-independent signaling pathway. J Biol Chem 279: 42709-42718, 2004.

34. Raffetto JD, Vasquez R, Goodwin DG and Menzoian JO Mitogen-activated protein kinase pathway regulates cell proliferation in venous ulcer fibroblasts. Vasc Endovascular Surg 40: 59-66, 2006. 